\title{
Target Sign en Tumores Neurogénicos
}

\section{Target Sign in Neurogenic Tumors}

\author{
J. I. Bernasconi ${ }^{1} \quad$ M. R. Mazzucco ${ }^{1}$ \\ ${ }^{1}$ Servicio de Diagnóstico por Imágenes, Hospital Universitario \\ Fundación Favaloro, Buenos Aires, Argentina \\ Rev Argent Radiol 2018;82:50-51.
}

El target sign es un signo radiológico descrito en los tumores de nervios periféricos. Está representado por un área central hipointensa, rodeada por una zona periférica hiperintensa, y se visualiza en secuencias ponderadas en $\mathrm{T} 2$ de resonancia magnética $(\mathrm{RM})^{1,2}$ (- Figs. 1 y 2). Ese signo fue comunicado por primera vez en la literatura por Suh y col. en el año $1992 .{ }^{2}$

Los hallazgos están íntimamente relacionados con las características histológicas del tumor. El área central hipointensa corresponde a un tejido conectivo, mientras que el área hiperintensa periférica se debe al tejido mixoide. ${ }^{3}$ Esa descripción se vincula con la densidad celular: cuantas más células tenga la lesión, su aspecto

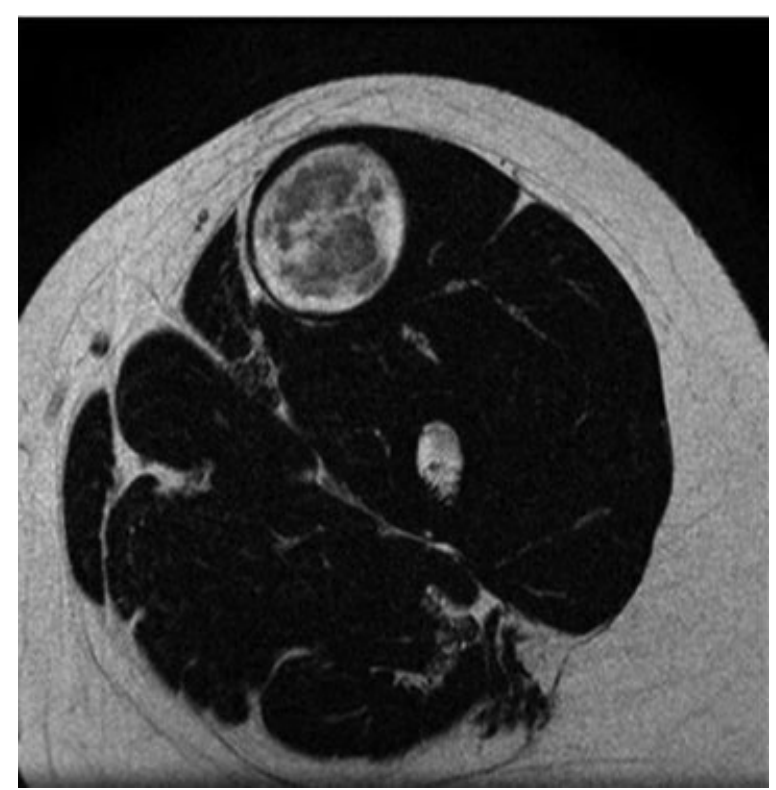

Fig. 1 Resonancia magnética en ponderación T2 de muslo izquierdo en corte axial, muestra una lesión de bordes definidos con centro hipointenso y un halo hiperintenso (target sign).

received

January 3, 2017

accepted

July 3, 2017
DOI https://doi.org/

$10.1055 / \mathrm{s}-0038-1639573$.

ISSN 1852-9992.
Address for correspondence Juan I. Bernasconi, Servicio de Diagnóstico por Imágenes, Hospital Universitario Fundación Favaloro, Buenos Aires, Argentina

(e-mail: juanignaciobernasconi18@hotmail.com).

será más hipointenso; mientras que a menor componente celular, la lesión se visualizará más hiperintensa.

Entre los tumores de nervios periféricos se destacan los neurofibromas, los schwannomas (ambos de características benignas) y los tumores malignos de esa etiología.

La distribución celular del target sign se observa con más frecuencia en los neurofibromas, mientras que en los schwannomas el componente celular tiene una distribución más aleatoria. Sin embargo, cuando el target sign es visualizado en los schwannomas, la zona central hipointensa corresponde a las células Antoni $\mathrm{A}$ y la zona hiperintensa periférica corresponde a las células Antoni $\mathrm{B}^{3}$ (-Fig. 3). Las células Antoni A presentan un patrón más celular y las células Antoni B un patrón más hipocelular. En los casos de tumores malignos de nervios periféricos, las zonas que presentan el target sign contienen tejido benigno y el resto de las áreas del tumor representa la transformación maligna del tejido. ${ }^{3}$

Los neurofibromas y schwannomas corresponden aproximadamente al $10 \%$ de los tumores benignos de partes blandas. ${ }^{1}$ El rango etario afectado se encuentra entre los 20 y 50 años, sin predilección por sexo. Pueden ser lesiones únicas (aproximadamente 90\%) o múltiples. ${ }^{4}$

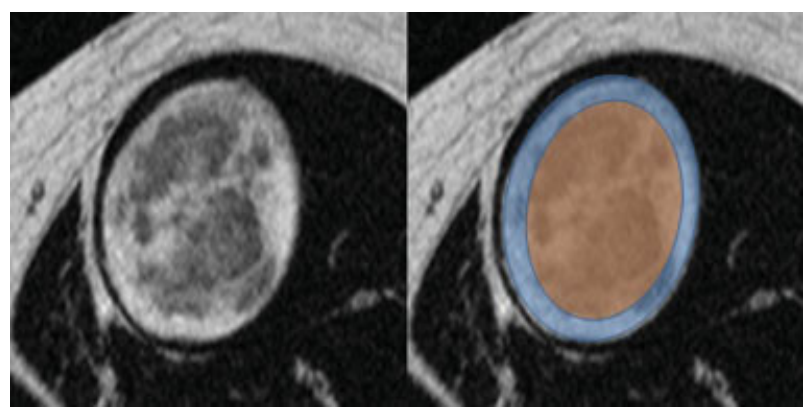

Fig. 2 Representación gráfica del target sign.

Copyright @ 2019, Sociedad Argentina de Radiología. Publicado por Thieme Revinter Publicações Ltda., Rio de Janeiro, Brazil. Todos los derechos reservados.

\section{License terms}

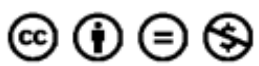




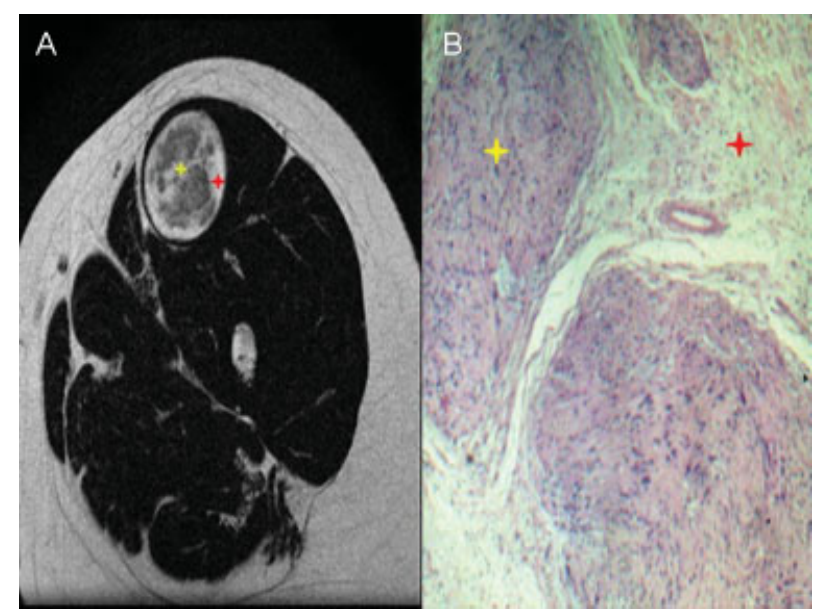

Fig. 3 (A) Target sign de un schwannoma en resonancia magnética y (B) su correlato anatomopatológico. El área central hipointensa corresponde a la zona celular Antoni A (estrella amarilla), mientras que la zona periférica hiperintensa corresponde a la zona celular Antoni B (estrella roja).

Generalmente los schwannomas comprometen raíces espinales y simpáticas en la cabeza y el cuello, la superficie flexora de las extremidades superiores e inferiores (especialmente el nervio cubital y el peroneo), el mediastino y el retroperitoneo, aunque otras veces puede afectar regiones poco usuales. $^{2-4}$

Clínicamente suelen ser asintomáticos, a menos que la tumoración comprima estructuras vecinas y genere sintomatología por compresión extrínseca. En los grandes nervios, el tumor es móvil, excepto a lo largo del eje largo del nervio donde la fijación restringe la movilidad. ${ }^{2-4}$
Los tumores malignos del nervio periférico, a diferencia de los benignos, tienden a ser más grandes, de bordes irregulares y rápido crecimiento. ${ }^{5}$

El tratamiento suele ser quirúrgico si se produce sintomatología por compresión extrínseca o hay sospecha de degeneración maligna. ${ }^{2-4}$

\section{Conclusión}

Es fundamental que el médico radiólogo reconozca el target sign y su asociación con los tumores de nervios periféricos. Si bien es más frecuente la etiología benigna, debemos tener presente el tumor maligno de la vaina de nervio periférico y plantearlo como un posible diagnóstico diferencial al momento de confeccionar el informe.

\section{Bibliografía}

1 Kransdorf MJ. Benign soft-tissue tumors in a large referral population: distribution of specific diagnoses by age, sex, and location. AJR Am J Roentgenol 1995;164(02):395-402

2 Suh JS, Abenoza P, Galloway HR, Everson LI, Griffiths HJ. Peripheral (extracranial) nerve tumors: correlation of MR imaging and histologic findings. Radiology 1992;183(02):341-346

3 Banks KP. The target sign: extremity. Radiology 2005;234(03): 899-900

4 Weiss SW, Goldblum JR. Benign tumors of peripheral nerves. In: Weiss SW, Goldblum JR, Folpe AL, eds. Enzinger and Weiss's soft tissue tumors. 5th ed. Philadelphia, Pa: Mosby Elsevier; 2007: 825-901

5 Li CS, Huang GS, Wu HD, et al. Differentiation of soft tissue benign and malignant peripheral nerve sheath tumors with magnetic resonance imaging. Clin Imaging 2008;32(02):121-127 